\title{
A microanatomical and histological study of the postcranial dermal skeleton of the Devonian actinopterygian Cheirolepis canadensis
}

Louise Zylberberg, François J. Meunier, and Michel Laurin

Acta Palaeontologica Polonica 61 (2), 2016: 363-376 doi:http://dx.doi.org/10.4202/app.00161.2015

The Devonian stem-actinoterygian Cheirolepis canadensis is potentially important to understand the evolution of the

dermal skeleton of osteichthyans, but the last detailed histological study on this taxon was published more than forty years ago. Here, we present new data about the morphology and the histological structure of scales, fulcra, and fin-rays in the Devonian actinopterygian Cheirolepis canadensis through SEM and photomicroscopy. The scales have a typical palaeoniscoid organisation, with ganoine layers overlaying dentine and a bony basal plate, but the ganoine surface lacks the characteristic microtubercles that have been described on the ganoine surface of the scales of polypterids and many other actinopterygians. Fin-rays are composed of segmented and ramified lepidotrichia that show a structure reminiscent of scales, with ganoine and dentine components lying on a thick bony base. We describe articular processes between lepidotrichia that are reminiscent of, and plausibly homologous with, the peg-and-socket articulations between the scales. The analysis of the postcranial dermal skeleton of Cheirolepis canadensis shows that structural similarities between scales and lepidotrichia of this basal actinopterygian are greater than in more recent actinopterygians. The new data on histological and microanatomical structure of the dermal skeleton lend additional support to the hypothesis that lepidotichia are derivatives of scales, though they are also compatible with the more general hypothesis that scales, lepidotrichia and fulcra belong to the same morphogenetic system.

Key words: Actinoterygia, Cheirolepis, scales, ganoine, dentine, paleohistology, Devonian, Canada.

Louise Zylberberg [louise.zylberberg@upmc.fr], Sorbonne Universités, UPMC Université Paris VI, UMR 7193, ISTEP, 4 place Jussieu, BC19, 75252 Paris cedex 05, France; CNRS, UMR 7193, ISTEP, Paris, France. François J. Meunier [meunier@mnhn.fr ], UMR 7208 (CNRS-IRD-UPMC-MNHN), BOREA, Département des Milieux et Peuplements Aquatiques, Muséum national d'Histoire naturelle, C.P. 026, 43 rue Cuvier, 75231 Paris cedex 05, France. Michel Laurin [laurin@mnhn.fr] (corresponding author), CR2P (UMR 7207, CNRSMNHNUPMC-U. Paris 6), Centre de Recherches sur la Paléobiodiversité et les Paléoenvironnements, Muséum National d'Histoire Naturelle, Bâtiment de Géologie, C P 48, 43 rue Buffon, F-75231, Paris Cedex 05 France. 
This is an open-access article distributed under the terms of the Creative Commons

Attribution License (for details please see creativecommons.org), which permits unrestricted use, distribution, and reproduction in any medium, provided the original author and source are credited.

Farf Full text $(1,268.8 \mathrm{kB})$ 